\title{
PROPOSTA DE IMPLEMENTAÇÃO DE MARKETING DIGITAL E DE SERVIÇOS PARA CAPTAÇÃO DE NOVOS CLIENTES: ESTUDO DE CASO NA EMPRESA SAINT FARMA DROGARIA
}

\section{ARTIGO ORIGINAL}

SILVA, Ana Maria Pontes da ${ }^{1}$, UCHOA, Ragyla Bianca Viana², COSTA, Samuel Dias $\mathrm{da}^{3}$, OLIVEIRA, Maria Socorro Silva $\mathrm{de}^{4}$, ALMEIDA, Victor da Silva ${ }^{5}$, SANTOS JÚNIOR, Aldemir Pereira dos ${ }^{6}$, ROBERTO, José Carlos Alves $^{7}$

SILVA, Ana Maria Pontes da. Et al. Proposta de implementação de marketing digital e de serviços para captação de novos clientes: estudo de caso na empresa Saint Farma Drogaria. Revista Científica Multidisciplinar Núcleo do Conhecimento. Ano. 06, Ed. 11, Vol. 02, pp. 62-82. Novembro 2021. ISSN: 24480959, Link de acesso: https://www.nucleodoconhecimento.com.br/administracao/novos-clientes, $\quad$ DOI: 10.32749/nucleodoconhecimento.com.br/administracao/novos-clientes

\section{RESUMO}

O presente artigo apresenta um estudo de caso realizado na Empresa Semog's Comércio de Medicamentos LTDA, que atua no seguimento de revendedora de medicamentos, sendo considerada de pequeno porte. Descreve os resultados dos estudos oriundos do problema de pesquisa identificado no diagnóstico realizado na organização, apontando-se o marketing como a área com maior necessidade de

\footnotetext{
${ }^{1}$ Graduanda do curso de Administração.

${ }^{2}$ Graduanda do curso de Administração.

${ }^{3}$ Graduando do curso de Administração.

${ }^{4}$ Graduanda do curso de Administração.

${ }^{5}$ Coorientador. Mestre em Engenharia de Processos. Pós-Graduando em Neuropsicopedagogia Institucional. Especialista em Gestão Estratégica de RH. Graduado em Administração e Pedagogia.

${ }^{6}$ Coorientador. Mestre em Ciências do Ambiente e Sustentabilidade na Amazônia. Especialista em Gestão dos Recursos Naturais e Meio Ambiente. Especialista em Metodologia do Ensino Superior. Graduado em Turismo e Administração.

${ }^{7}$ Orientador. Mestrado profissional em Engenharia de produção. Especialização em Gestão em Logística empresarial. Graduação em Administração com Ênfase em Marketing.
}

RC: 100622

Disponível em: https://www.nucleodoconhecimento.com.br/administracao/novosclientes 
incrementos em sua gestão. Sendo assim, a partir de estudos preliminares a respeito do tema, definiu-se a questão norteadora: Como estratégias de capacitação voltadas ao marketing de serviços e ao digital, integradas ao atendimento na empresa, podem amplificar o desempenho das vendas? Mediante o desejo de formular soluções à problemática abordada, estabelece-se como objetivo geral estipular a abordagem voltada à identificação e à introdução de técnicas voltadas ao marketing digital e aos serviços que podem incrementar o desempenho das vendas na gestão do Marketing da organização. A metodologia empregada neste artigo caracteriza-se como qualitativa, exploratória e com fins bibliográficos. Para execução das ações interventivas elaboradas, utilizar-se-á de um instrumento interventivo 5W2H para redigir-se ações de aprimoramento interno, para, por meio deste estudo, instaurar-se treinamentos para o gerenciamento das operações na loja física, com vistas à prospecção de novos clientes, desenvolvimento de estratégias em marketing digital e gerenciamento de serviços terceirizados de delivery. Como resultados, identificou-se que as propostas de introdução de capacitações voltadas ao aprimoramento gerenciamento da loja física, bem como treinamentos para prospecção de clientes e desenvolvimento de estratégias de marketing digital, aliadas ao treinamento para gerenciamento dos serviços terceirizados de entrega, esquematizam um conjunto de ações interventivas que podem redirecionar os processos a novos índices de eficiência em suas operações e, por conseguinte, ampliar o desempenho das vendas.

Palavras-chave: Ação, Estratégias, Marketing, Medicamentos.

\section{INTRODUÇÃO}

No âmbito corporativo, que possui alto grau de complexidade e o percurso ao sucesso cada vez mais acirrado, requer-se que as organizações elaborem inovações constantes, visto que, para prevalecer-se sobre os adversários, é primordial formular soluções às oposições do mundo dos negócios. Nesse sentido, atender os consumidores e todos os seus desejos deve ser o foco para que todas as ações e táticas guiadas pela tecnologia contribuam para sanar os desejos dos

RC: 100622

Disponível em: https://www.nucleodoconhecimento.com.br/administracao/novosclientes 
consumidores que prezam pela qualidade e o custo-benefício, afinal, este é um dos melhores métodos voltados ao crescimento institucional. Desta forma, implementase o referido estudo, executado na Empresa Semog's Comércio de Medicamentos LTDA., caracterizada por pequeno porte e pela prestação de serviços voltados à revenda de medicamentos, cuja mesma subordina-se às constatações elucidativas apresentadas pelo diagnóstico organizacional.

Conforme o entendimento do setor de Marketing, este evidencia-se como o de maior criticidade entre os setores apontados nos gráficos. Verifica-se a necessidade de praticar hábitos propícios e vantajosos, internamente e externamente. De encontro a este pressuposto, o objetivo geral estipula a abordagem voltada à identificação e à introdução de técnicas voltadas ao marketing digital e de serviços que podem incrementar o desempenho das vendas na gestão do Marketing da empresa. Souza et al. (2019) ressaltam que após a definição do que se deseja abordar, torna-se necessário formular a questão da problematização, questionamento este que deve delimitar as bases ao que pesquisar. Os autores salientam que na questão de pesquisa, diversas são as variáveis. Segundo o relato dos pesquisadores, indagouse e concebeu-se a seguinte questão: Como estratégias de capacitação voltadas ao marketing de serviços e ao digital, integradas ao atendimento na empresa, podem amplificar o desempenho das vendas?

Nota-se a forte carência deste setor, sendo assim, com os conhecimentos tratados no estudo, mostra-se, a seguir, a obstinação em adotar estratégias de gerenciamento, como as ferramentas abordadas no setor de serviços formuladas pelo marketing, o que inclui o desenvolvimento de táticas digitais de comercialização. A pesquisa busca todas estas soluções, conforme as técnicas qualitativa, exploratória e bibliográfica, tangendo as ações fundamentadas na ferramenta $5 \mathrm{~W} 2 \mathrm{H}$. Nos conceitos referentes a serviços e marketing, o centro deve ser a total satisfação do consumidor, o que torna necessário à instituição renovar-se para sempre suprir todas suas expectativas e fidelizá-lo. Uma nova estrutura organizacional pretende modificar o setor de marketing, sendo esta por meio digital, 
e busca reestruturar-se e adaptar-se às constantes inovações. Ela é responsável por publicitar e divulgar os serviços e produtos, bem como atrair clientes.

Sendo assim, as propostas salientadas neste estudo firmam a utilização do digital para desenvolver capacitação referente a todas estas atribuições do setor e de demais segmentos. Disponibiliza-se a solidificação conforme os objetivos específicos de: explorar as formas de treinamento em marketing de serviços; abordar a inserção de tais treinamentos na loja física e balcão virtual; e dimensionar os resultados obtidos com a abordagem das técnicas de serviço aplicadas. A área de Marketing tem a incumbência de explorar, criar e acrescentar valores à corporação, bem como aos seus produtos e serviços, de modo a proporcionar satisfação aos clientes, o que, em decorrência, resulta em lucros, conforme o valor gerado com o relacionamento e sua audiência. Consequentemente, visa-se, mediante às ações sugestionadas, a capacitação dos colaboradores para melhor gerenciamento das operações na loja física, na prospecção de atrair novos clientes, almejando, ainda, o desenvolvimento de estratégias em marketing digital e o gerenciamento de serviços terceirizados de delivery.

\section{FUNDAMENTAÇÃO TEÓRICA}

Conceitua-se fundamentação teórica como o desenvolvimento investigativo necessário ao embasamento do tema em referência, balizando, portanto, os tópicos relevantes para a pesquisa, inserindo-se as questões a serem contestadas, os objetivos almejados, o enredo a ser abordado e as apologias, com a finalidade de transformá-las em proveitosas. De acordo com Ferreira (2014, p. 429), a fundamentação teórica serve para "[...] o autor mostrar que conhece a literatura relevante em que posiciona seu artigo. Além disso, [...] aqui, o autor mostra sua maestria e que entende os conceitos fundamentais. Importa, assim, construir uma revisão de literatura bem focada [...]". 


\subsection{CONCEITO DE MARKETING}

É possível compreender marketing como o segmento que correlaciona publicidade e propaganda no setor empresarial. Hodiernamente, este setor tem passado por diversas modificações conforme a transformação do meio digital. Deste modo, diversos conceitos passaram a ser atribuídos ao segmento. Segundo Toledo e Moretti (2016), esta concepção refere-se à gestão do valor que o usuário recebe, é o resultado do amparo a uma série de instruções sobre o mercado que a companhia adota. É nesta razão que se esculpem as ações de marketing direcionadas à formulação e engrandecimento de valor distinto ao cliente, com vistas a cativar, fascinar e sustentar sua aquisição.

No entanto, esta área constitui capacidade de agregar os mais diversos negócios e seu foco sempre é o cliente, atendê-lo da melhor maneira possível e suprir todos os seus anseios. Visa-se desenvolver uma série de táticas que envolvem todo o processo de desenvolvimento, interlocução e produção de valores abstratos (ou não) aos itens e serviços. Na base do marketing, reconhece-se o desejo de formular e manter relacionamentos não somente com os consumidores, mas também com todos os demais stakeholders. Assis e Oliveira (2012) formulam que marketing é a ação e as aglomerações de conduta e processos que devem formular, informar, oferecer e modificar ofertas que agregam valor aos clientes e empresas, de forma geral. Tais ofertas compõem produtos palpáveis e impalpáveis, como a empreitada do estudo em destaque.

\subsubsection{MARKETING DE SERVIÇOS}

Serviços são descritos como atividades que envolvem valores monetários, cujo indivíduo oferta algo e quem recebe o serviço toma posse, mas não se torna o dono deste em questão, isto por não se tratar de algo físico e palpável, no entanto, está correlacionado a algum desempenho. Formulam-se alguns conceitos que influenciam diretamente o desenvolvimento do marketing de serviços, como a 
intangibilidade, a inseparabilidade, a variabilidade e a perecibilidade. Todos os estes, conceitos que não incluem itens físicos a serem produzidos.

Para Assis e Oliveira (2012), a proeminência em marketing de serviços requer elevação de uma tríade globalizante, sendo esta: o Marketing Externo, que refere-se ao desempenho do preparo, preços fixados, diálogo e entrega dos serviços aos seus consumidores; Marketing Interno, que favorece o desempenho de capacitação e motivação dos colaboradores em atenção aos clientes; e o Marketing Interativo, concerne à aptidão do colaborador em proporcionar ao cliente aquilo que necessita, visto que são avaliados por suas qualificações táticas e operacionais.

\subsubsection{MARKETING DIGITAL}

A era digital proporciona, nesse contexto, uma maior flexibilidade no que concerne à formulação de novos comércios, de modo que, atualmente, na rede de internet, encontra-se amplos leques voltados aos mesmos produtos ou serviços. Sendo assim, cabe ao profissional de marketing, o atendimento a certos requisitos, como o bom manuseio de técnicas e procedimentos específicos, chamar a atenção do consumidor e convencê-lo a realizar a aquisição. Para Lemes e Ghisleni (2013), o meio digital é tão chamativo aos indivíduos, pois recorre aos desejos básicos primordiais e em constante modificação. As mídias sociais são grandes facilitadoras deste preceito, afinal, é por meio delas que se torna possível expor conceitos, ideias e produções gráficas (com sons e imagens).

No setor marqueteiro, um modelo voltado a valer-se de vias divulgadoras e disseminadoras das tecnologias é o reconhecido como marketing digital. Este envolve todo o comércio que é desenvolvido nas mídias sociais. Tal ramo tornou-se necessário conforme o pensamento do consumidor transformou-se, tornando-se, de certo modo, mais exigente no momento da compra, de modo que, com mais exigências, há maiores expectativas a cumprir e o marketing digital busca compreender estas expectativas para ofertar produtos condizentes com as necessidades dos clientes. Conforme Silva e Cruz (2014, p. 03), o marketing digital é

$\mathrm{RC}: 100622$

Disponível em: https://www.nucleodoconhecimento.com.br/administracao/novosclientes 
aquele "que se utiliza de canais eletrônicos como a internet para expandir a relação entre organizações e clientes [...] é diferente do marketing tradicional, devido o mesmo divulgar a imagem de uma organização através da utilização da internet [...]".

\subsubsection{MARKETING DE RELACIONAMENTO}

Como compreende-se o conceito de relacionamento como ligação entre algo ou alguém, no marketing de relacionamento, busca-se estabelecer uma relação entre os clientes e as corporações. Deste modo, esta metodologia anseia estabelecer fortes, duradouras e satisfatórias ligações com todos os envolvidos, desde fornecedores a consumidores finais.

A organização que firma o parecer do cliente como prioridade sobre os serviços deve valer-se dessa ferramenta para agregar melhores resultados e possibilitar a elevação diante dos concorrentes. Todas as táticas abordadas neste modelo de marketing visam o desenvolvimento de melhores vínculos com todos, no entanto, a priori, com os clientes finais.

Para Lemes e Ghisleni (2013, p. 07), “a vantagem de alta visibilidade das mídias sociais e os relacionamentos das redes sociais com grande interatividade é o que as tornam atraentes para o marketing digital $[\ldots . .$.

\subsubsection{GERENCIAMENTO POR PROCESSOS}

É possível categorizar o conceito de processos organizacionais em duas classes, a dos finalísticos, que, interligados a outros, são diretamente envolvidos na produção dos itens, e os de apoio, que, por sua vez, são aqueles que não envolvem contato direto com os produtos, sendo estes os gerenciais e decisórios. Conforme Cunha (2012, p. 10), "para a consecução de cada tipo de processo da organização, é necessária a articulação de diversas ações que podem se desdobrar na execução de subprocessos, etapas e atividades [...]".

$\mathrm{RC}: 100622$

Disponível em: https://www.nucleodoconhecimento.com.br/administracao/novosclientes 
Neste sentido, encontra-se o conceito de gerenciamento por processos que contempla a organização como um todo para só então focar em um único processo específico, isto para visualizar sua conexão com os demais. Silva (2014, p. 25) fórmula que neste modelo de gerenciamento existem "[...] vários objetivos. Dentre eles, pode-se destacar: a agregação de valor ao produto/serviço na percepção do cliente; o aumento da competitividade; o aumento da qualidade; além da simplificação dos processos organizacionais [...]". É um conceito que se compreende como a base do marketing, sendo assim, entende-se que há uma relação entre tais, ressaltando-se que o conceber de sua interligação é formulado mediante a inserção de tecnologias da informação.

\subsubsection{SERVIÇOS DE DELIVERY}

Não é novidade que os meios de comunicação têm proposto à sociedade serviços cada vez mais práticos e com melhores atribuições, no entanto, a grande modificação no uso de serviços delivery passou a ocorrer em decorrência do início do quadro pandêmico provocado pela Covid-19 que o mundo enfrenta. $O$ crescimento acelerado destes serviços advém da necessidade e da praticidade presente nestes conceitos. Mediante a isto, Beltrão (2019) salienta que a popularidade atual dos aplicativos de entrega para terceirização de delivery advém da busca social pela constante comodidade e agilidade, o qual, por sua vez, deve priorizar nas organizações o desenvolvimento da originalidade do método de oferta dos serviços, bem como o modo como estes serão ofertados aos consumidores finais.

\subsection{CAPACITAÇÃO COMO FERRAMENTA EMPRESARIAL}

$\mathrm{Na}$ formulação das sociedades, os indivíduos passaram a buscar conhecimentos e maior aprendizagem, isto conforme surgiu a necessidade do desenvolvimento e aprimoramento da economia, no entanto, um outro preceito que está fortemente interligado ao desejo de aquisição de conhecimentos envolve a realização pessoal de cada pessoa. No contexto empresarial, por conta da competitividade corporativa,

$\mathrm{RC}: 100622$

Disponível em: https://www.nucleodoconhecimento.com.br/administracao/novosclientes 
a partir da segunda metade dos anos 50, as organizações passaram a compreender que a capacitação empresarial é uma forte ferramenta que gera vantagem competitiva, pois tais empresas tornaram-se líderes em seus mercados justamente por este preceito.

Menegon e Zambarda (2019) abordam o conceito de capacitação empresarial como uma atividade contínua a qual necessita suprir o pressuposto de constante renovação educacional, justamente para suprir as faltas que o modelo padrão demonstra. Com as táticas de constante renovação instauradas na organização, as atividades passam a ser desenvolvidas internamente e, dessa forma, tornam-se mais firmes e com menor risco de falhas, de modo que a formação continuada deve andar em conjunto com as atividades e com os processos organizacionais.

\subsubsection{TREINAMENTOS EM EAD}

O crescimento organizacional, com este novo momento tecnológico, tem angariado grandes ferramentas capazes de superar a competitividade, desta forma, assim como outros diversos recursos são fonte de vantagem, o uso da tecnologia em diversos âmbitos é de grande relevância. A internet desde sua integração global impulsiona o crescimento constante que tem se tornado cada vez mais forte, de modo que a comunicação se torna de certo modo mais acessível e simplificada, sendo assim, a educação e muitos outros setores passaram a adaptar-se a esta nova realidade.

Albertin e Brauer (2012) elucidam que a formulação da educação à distância ou EAD, como é comumente reconhecida, não ocorre somente no meio acadêmico, no ambiente empresarial, na reconhecida Educação Corporativa (EC), os conceitos de EAD e suas técnicas de procedimentos de capacitação vem sendo recorridos para transmitir melhores ensinamentos, isto por esse método contemplar diversas vantagens e uma destas ser a dispensabilidade de locomoção ao ambiente presencial de estudo. Todos esses fatores fazem com que o online seja acomodado cada vez mais.

RC: 100622

Disponível em: https://www.nucleodoconhecimento.com.br/administracao/novosclientes 


\section{MATERIAIS E MÉTODOS}

Segundo Ferreira (2014), a divisão de método é comparativamente comum se houver cautela na descrição dos mecanismos relacionados a reunião de dados, o que implica discorrer sobre amostragens, dispositivos, variáveis e técnicas das análises dos fatos

\subsection{PROCEDIMENTOS METODOLÓGICOS}

Ferreira (2014, p. 431) afirma que "o que deve incluir nesta seção é uma descrição do método usado, mas com o detalhe suficiente para o leitor conseguir entender e, se desejar, replicar [...]".

\subsubsection{QUANTO À NATUREZA}

Segundo Kripka; Scheller e Bonotto (2015, p. 57), "em uma pesquisa qualitativa pode-se utilizar vários procedimentos e instrumentos de constituição e análise de dados, entre estes a pesquisa documental [...]".

Minayo (2017) afirma que a pesquisa qualitativa visa à veemência das manifestações, isto é, indica a grandeza sociocultural e a exterioriza por meio das crenças, dos valores, sugestões, ilustrações, bem como aponta-se maneiras de relacionar-se, personificações, hábitos comportamentais e suas práticas, preocupando-se minimamente com os aspectos repetitivos.

Deste modo, este estudo fixa sua natureza na metodologia de pesquisa qualitativa, isto por esta buscar compreender e informar de forma clara a relevância dos acontecimentos ocorridos na pesquisa.

\subsubsection{QUANTO AOS FINS}

Souza et al. (2019), declaram que a pesquisa exploratória se identifica pelo desdobramento e elucidações de concepções, com a intenção de proporcionar uma

RC: 100622

Disponível em: https://www.nucleodoconhecimento.com.br/administracao/novosclientes 
visão geral, uma prévia afluência de um fato específico raramente sondado. Denomina-se também como pesquisa de base porque disponibiliza dados essenciais relevantes à veracidade do estudo em questão. Conforme Pereira, Castilho e Borges (2011), o método exploratório refere-se à inquirição de pesquisa experimental, que se objetiva a criação de questionamentos ou de uma problemática, cujo fim é expor suposições, fomentando-se a ligação do pesquisador com o espaço, situações ou eventos, ligação esta necessária à concretização de uma esmiuçada investigação posterior.

Quanto aos fins desta pesquisa, recorreu-se aos procedimentos exploratórios para a obtenção de uma visão mais ampla dos dados, com vistas a compreender com clareza quais informações são, de fato, relevantes ao estudo.

\subsubsection{QUANTO AOS MEIOS}

Para Pereira; Castilho e Borges (2011), a pesquisa bibliográfica fundamenta-se na ponderação de diversas fontes referentes à temática eleita para concretização do estudo. Envolve, geralmente, as referências bibliográficas vistas com sapiência atribuídas a publicações, monografias, periódicos e outros.

De acordo com Souza et al. (2019), uma pesquisa desta índole antecede-se a outra, contando com mais narrativas e mais esclarecimentos, dispondo-se de minuciosas investigações do setor ou da temática em questão.

Por meio da metodologia bibliográfica, tornou-se possível abordar os métodos exploratórios, deste modo, recorreu-se a este critério para abordar de modo aclarado todos os dados anteriormente coletados e descrever quais os relevantes ao estudo em questão.

\subsection{CARACTERIZAÇÃO DA EMPRESA}

Este estudo de caso foi realizado na Empresa SEMOG'S Comércio De Medicamentos Ltda., que atende ao nome fantasia Saint Farma Drogaria, localizada

RC: 100622

Disponível em: https://www.nucleodoconhecimento.com.br/administracao/novosclientes 
na Avenida Torquato Tapajós, 9250 - Colônia Terra Nova - Manaus/Am, CEP: 69093-415. A organização Saint Farma Drogaria é uma sociedade classificada como de pequeno porte. Atua principalmente no segmento da comercialização de produtos farmacêuticos, cosméticos, perfumaria, além de oferecer exames diversos. A Drogaria, atualmente, conta com cerca de 2 sócios e 4 colaboradores que desenvolvem as atividades comerciais. Sua estrutura possui $50 \mathrm{~m}^{2}$, piso único, dividido entre salão de vendas, escritório, estoque e consultório para aplicação de intravenosas e cutâneas.

Tais características atribuem forma ao ambiente analisado. Todo o espaço formulado conta com a melhor iluminação e ventilação possível, sempre condizente aos serviços prestados, deste modo, tudo é muito bem estruturado e higienizado, garantindo-se, com isso, total cuidado aos colaboradores e clientes. A farmácia conta com rigorosos controles periódicos de dedetização para que não haja comprometimento na qualidade das instalações, bem como considera os demais problemas a sua clientela. Além de todo esse cuidado, o aparato de segurança básica é completo e conforme o recomendado pelas organizações de saúde e demais organizações de segurança.

\section{RESULTADOS E DISCUSSÕES}

As observações realizadas ao longo da pesquisa têm como base os dados fornecidos pelo Diagnóstico Organizacional da empresa Saint Farma, na qual constatou-se a imprescindibilidade de intercessões nas áreas adiante justificadas. Salienta-se que, em adesão a esta investigação, corroboram-se aparatos para a dissipação das hesitações avistadas no setor de marketing da corporação em questão, ressaltando-se, assim, que o setor financeiro se apresenta com a melhor situação. Dando seguimento, as razões que motivaram a média desta diligência organizacional da corporação ocorreram de acordo com o que é apontado a seguir, no gráfico 01: medição de desempenho.

RC: 100622

Disponível em: https://www.nucleodoconhecimento.com.br/administracao/novosclientes 
Gráfico 01 - Média - Desempenho por Área Funcional

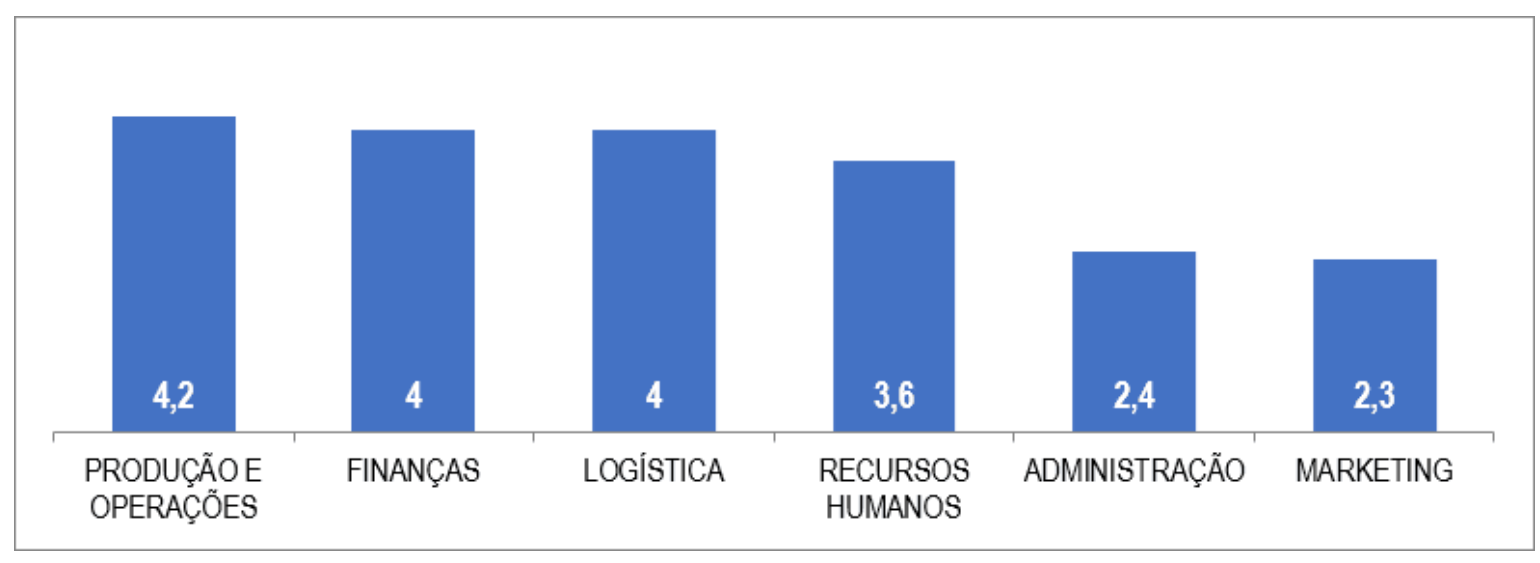

Fonte: Autores, 2021.

De acordo com o que se expõe acima, percebe-se que a empresa Saint Farma tem o melhor desempenho no setor das finanças, seguido pelo operacional, bem como nos setores de logística, administrativo e recursos humanos, rotulando como setor mais crítico da empresa o marketing. Sendo assim, julga-se que o setor em questão requer maior fugacidade de recursos, de modo que possam subsidiar aptidões associadas aos procedimentos intrínsecos. Conforme o averiguado no gráfico 01 , reitera-se, no setor de Marketing, a necessidade aprofundada e inadiável de aspectos pertinentes à problemática organizacional, de maneira que, com as devidas comutações, ocorram-se os resultados necessários ao melhor desenvolvimento organizacional.

Quadro 01 - Marketing

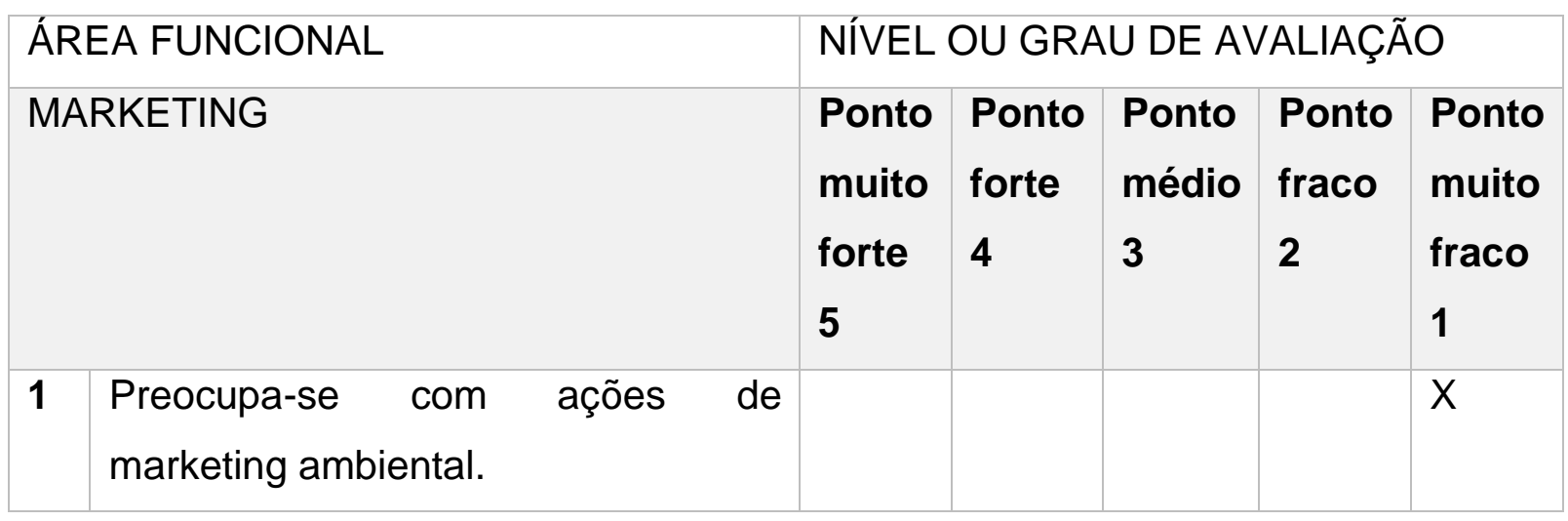

RC: 100622

Disponível em: https://www.nucleodoconhecimento.com.br/administracao/novosclientes 


\begin{tabular}{|c|c|c|c|c|c|c|}
\hline 2 & $\begin{array}{l}\text { Padroniza-se o processo de } \\
\text { produção dos itens. }\end{array}$ & & & $x$ & & \\
\hline 3 & $\begin{array}{l}\text { Demonstra-se variedade de produtos } \\
\text { âncora. }\end{array}$ & & & & $X$ & \\
\hline 4 & $\begin{array}{l}\text { Apresenta-se preços competitivos } \\
\text { com o mercado. }\end{array}$ & & & & & $X$ \\
\hline 5 & $\begin{array}{l}\text { Localiza-se a empresa de modo } \\
\text { favorável às vendas. }\end{array}$ & & & $X$ & & \\
\hline 6 & $\begin{array}{l}\text { Dispõe-se de estratégias de } \\
\text { comunicação visual. }\end{array}$ & & & & $X$ & \\
\hline 7 & $\begin{array}{l}\text { Detém-se estratégias de divulgação } \\
\text { dos produtos e serviços. }\end{array}$ & & & & & $X$ \\
\hline 8 & $\begin{array}{l}\text { Divulgam-se produtos inovadores e } \\
\text { diferenciados. }\end{array}$ & & & $x$ & & \\
\hline 9 & $\begin{array}{l}\text { Estrutura-se o anseio pela captação } \\
\text { de novos clientes. }\end{array}$ & & $X$ & & & \\
\hline 10 & $\begin{array}{l}\text { Quantifica-se a satisfação dos } \\
\text { clientes. }\end{array}$ & & & $X$ & & \\
\hline \multicolumn{2}{|c|}{ TOTAL $(\Sigma)$} & 0 & 4 & 12 & 4 & 3 \\
\hline \multicolumn{2}{|r|}{ MÉDIA POR GRAU (POR COLUNA) } & 0 & 0,4 & 1,2 & 0,4 & 0,3 \\
\hline \multicolumn{2}{|r|}{ DESEMPENHO DA ÁREA $(\Sigma)$ TOTAL } & 2,3 & & & & \\
\hline
\end{tabular}

Fonte: Autores, 2021.

Mediante aos dados acima, é notório que os coeficientes na organização se rotulam do nível 4 , sendo o ponto forte ao nível 1 , sendo este o ponto muito fraco detectado. Foram lapidados por meio de trâmites particulares e embasados na coleta de dados e fatos ímpares à contestação. Em conformidade ao apontado, objetiva-se interpor métodos que acentuam ferramentas auxiliadoras a decifrar a problemática em evidência no setor de Marketing. Retrata-se a exata indagação de pesquisa em: Como estratégias de capacitação voltadas ao marketing de serviços e ao digital,

RC: 100622

Disponível em: https://www.nucleodoconhecimento.com.br/administracao/novosclientes 
integradas ao atendimento na empresa, podem amplificar o desempenho das vendas?

\subsection{PLANEJAMENTO DE AÇÕES}

Com o propósito de gerar melhorias na companhia e no respectivo setor abordado, forjou-se, mediante às análises, o quadro seguinte, sendo que no mesmo aborda-se como as Ações Interventivas exportadas para a integração de ferramentas podem auxiliar os colaboradores nas atribuições adaptáveis às necessidades da instituição.

Quadro 02 - Ações interventivas

\begin{tabular}{|l|l|l|l|l|}
\hline $\mathbf{0 1}$ & $\begin{array}{l}\text { Ações Interventivas } \\
\text { Treinamento para o gerenciamento } \\
\text { das operações na loja física }\end{array}$ & $\begin{array}{l}\text { Cronologia } \\
\text { Agosto/2021 }\end{array}$ & $\begin{array}{l}\text { Duração } \\
\text { Custo }\end{array}$ & $\begin{array}{l}\text { dias } \\
\mathrm{R} \$\end{array}$ \\
\hline $\mathbf{0 2}$ & $\begin{array}{l}\text { Treinamento para prospecção de } \\
\text { novos clientes }\end{array}$ & Setembro/2021 & 10 dias & $\mathrm{R} \$$ \\
\hline $\mathbf{0 3}$ & $\begin{array}{l}\text { Treinamento para desenvolvimento } \\
\text { de estratégias em marketing digital }\end{array}$ & Outubro/2021 & 10 dias & $\mathrm{R} \$$ \\
\hline $\mathbf{0 4}$ & $\begin{array}{l}\text { Treinamento para gerenciamento de } \\
\text { serviços terceirizados de delivery } \\
\text { TOTAL }\end{array}$ & Novembro/2021 & 02 dias & $\mathbf{R} \$$ \\
\hline & & & $1.000,000,00$ \\
\hline
\end{tabular}

Fonte: Autores, 2021.

Reafirma-se acima, de maneira programada e destacada, que as delegações visam à integração no setor de Marketing da companhia em análise. Ambiciona-se, com tais critérios que se retifiquem as falhas, a fluência no setor, controlando as ações de forma precisa, salientando-se a qualidade dos serviços dissertados pela empresa.

RC: 100622

Disponível em: https://www.nucleodoconhecimento.com.br/administracao/novosclientes 


\subsubsection{FERRAMENTA DA QUALIDADE PARA IMPLEMENTAÇÃO $5 \mathrm{~W} 2 \mathrm{H}$}

Esta metodologia reconhecida como matriz $5 \mathrm{~W} 2 \mathrm{H}$, tem como objetiva e visa estruturar ações específicas, almejando-se a melhor evolução organizacional, formulada a partir dos termos em inglês: what, why, who, where, when, how e how much. Tais palavras estabelecem conceitos de: período, afazeres, equipes, bases organizacionais, erários e procedimentos. Segundo Dutra (2018, p. 33), "[...] as etapas traduzidas do inglês, que é de onde deriva o nome [...] Who? (Quem); What? (O quê); Why? (Por quê); When? (Quando); How? (Como); Where? (Onde); How much? (Quanto) [...]".

\subsubsection{TREINAMENTO PARA O GERENCIAMENTO DAS OPERAÇÕES NA LOJA FÍSICA (5W2H)}

Sondou-se a organização e, conforme a heterogeneidade observada na base dos fatos, assegura-se, a partir do observado com a coleta de dados, a necessidade de demandar correções nos procedimentos voltados ao gerenciamento da corporação, de forma a organizar os processos de produção diários. Através do quadro 03 , destaca-se a preparação da introdução de tal treinamento voltado a este fim.

Quadro 03 - Treinamento para o gerenciamento das operações na loja física

\begin{tabular}{|l|l|l|}
\hline \multicolumn{4}{|l|}{ Treinamento para o gerenciamento das operações na loja física } \\
\hline What & O quê? & $\begin{array}{l}\text { Treinamento dos colaboradores para padronização dos } \\
\text { processos. }\end{array}$ \\
\hline Why & Por quê? & $\begin{array}{l}\text { Para aprimorar o gerenciamento de estoques e setores } \\
\text { produtivos, para possibilitar o correto suprimento das } \\
\text { necessidades do mercado. }\end{array}$ \\
\hline Where & Onde? & No setor produtivo da empresa. \\
\hline When & Quando? & Primeira semana de agosto de 2021. \\
\hline
\end{tabular}

RC: 100622

Disponível em: https://www.nucleodoconhecimento.com.br/administracao/novosclientes 


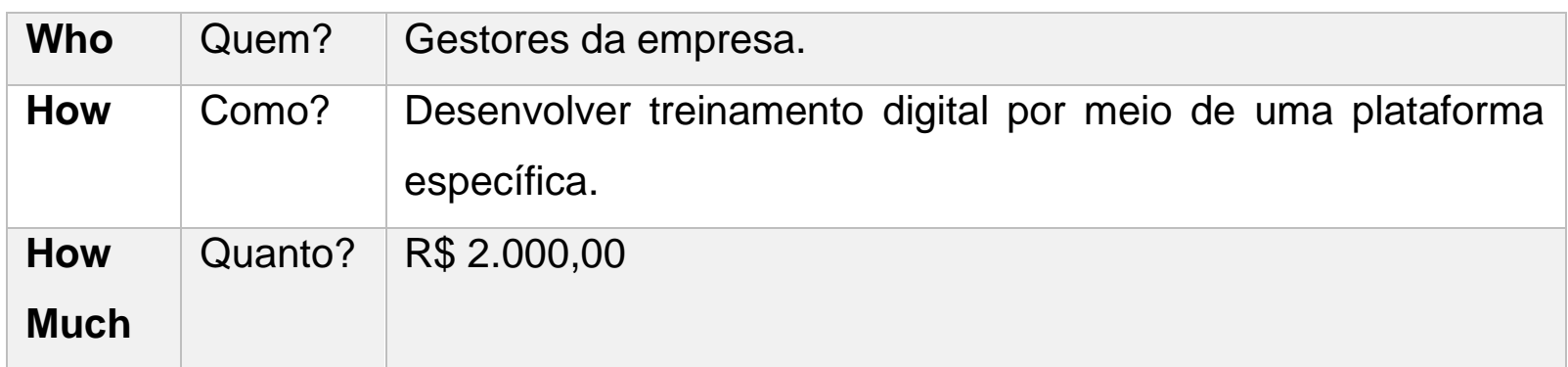

Fonte: Autores, 2021.

Exibe-se acima o propósito de aderir a ação voltada aos treinamentos específicos direcionados, por sua vez, ao gerenciamento das operações internas, sendo estes aplicados, diariamente, nesta área, sucedendo-se, conforme o cronograma, na primeira semana de agosto de 2021. Os gestores da instituição são os encarregados por desferi-la e objetiva-se que esta capacitação torne possível o aperfeiçoamento do gerenciamento das lojas, com boas práticas e programação estratégica para promover o aumento das vendas, além de suprir a demanda na empresa.

\subsubsection{TREINAMENTO PARA PROSPECÇÃO DE NOVOS CLIENTES $(5 \mathrm{~W} 2 \mathrm{H})$}

Caracteriza-se que na organização estabelece-se a indispensabilidade da adesão de medidas estratégicas e uso de ferramentas para impulsionar a área de comercialização. Estes procedimentos devem ocorrer para prospecção de novos clientes e para adequação dos resultados do faturamento da empresa, seja no setor físico ou virtual.

Quadro 04 - Treinamento para prospecção de novos clientes

\section{Treinamento para prospecção de novos clientes}

\begin{tabular}{|l|l|l|}
\hline What & O quê? & Capacitar os colaboradores para agregar novos públicos. \\
\hline Why & Por quê? & Para alcançar novos mercados. \\
\hline Where & Onde? & Setor de atendimento interno e externo. \\
\hline When & Quando? & Primeira semana de setembro de 2021. \\
\hline
\end{tabular}

RC: 100622

Disponível em: https://www.nucleodoconhecimento.com.br/administracao/novosclientes 


\begin{tabular}{|l|l|l|}
\hline Who & Quem? & Departamento administrativo e atendimento. \\
\hline How & Como? & $\begin{array}{l}\text { Desenvolver treinamento digital por meio de uma plataforma } \\
\text { específica. }\end{array}$ \\
\hline $\begin{array}{l}\text { How } \\
\text { Much }\end{array}$ & Quanto? & $\mathrm{R} \$ 4.800,00$ \\
\hline
\end{tabular}

Fonte: Autores, 2021.

Conforme o descrito acima, objetiva-se com este treinamento para os colaboradores aprimoramentos nos processos rotineiros da empresa. O plano se desenvolveu no setor de atendimento da organização, na primeira semana de setembro de 2021. O setor administrativo em companhia ao atendimento foram os encarregados pela aplicação da ação proposta. O treinamento buscou realizar progressos estratégicos, com $O$ intuito de otimizar as vendas e formular melhores relações entre empresa/cliente.

\subsubsection{TREINAMENTO PARA DESENVOLVIMENTO DE ESTRATÉGIAS EM MARKETING DIGITAL (5W2H)}

Com base nos dados contraídos, instituiu-se medidas estratégicas com a utilização das ferramentas para elevar as taxas de comercialização por meio do marketing digital. Destaca-se a seguir a ação que teve como intuito padronizar o planejamento por meio de treinamento na área de marketing digital, voltado à prospecção de novos públicos.

Quadro 05: Treinamento para desenvolvimento de estratégias em marketing digital

\begin{tabular}{|l|l|l|}
\hline \multicolumn{3}{|l|}{ Treinamento para desenvolvimento de estratégias em marketing digital } \\
\hline What & O quê? & $\begin{array}{l}\text { Aplicar treinamento de técnicas voltadas à propaganda } \\
\text { digital. }\end{array}$ \\
\hline Why & Por quê? & Para desenvolver o crescimento das vendas virtuais. \\
\hline Where & Onde? & Nos setores de marketing e atendimento. \\
\hline
\end{tabular}

RC: 100622

Disponível em: https://www.nucleodoconhecimento.com.br/administracao/novosclientes 


\begin{tabular}{|l|l|l|}
\hline When & Quando? & Primeira semana de outubro de 2021. \\
\hline Who & Quem? & Gestores da instituição. \\
\hline How & Como? & $\begin{array}{l}\text { Desenvolver treinamento digital por meio de uma plataforma } \\
\text { específica. }\end{array}$ \\
\hline $\begin{array}{l}\text { How } \\
\text { Much }\end{array}$ & Quanto? & $\mathrm{R} \$ 8.650,00$ \\
\hline
\end{tabular}

Fonte: Autores, 2021.

Mediante o especificado acima, visou-se a aplicação do treinamento para o aprimoramento do marketing digital entre os colaboradores filiados à empresa aqui analisada. As mudanças começaram a aparecer a partir da primeira semana de outubro de 2021, sobretudo nos setores de marketing e atendimento. Os gestores da instituição foram responsáveis pela ação proposta. Este treinamento aplicou-se conforme as estratégias de mercado voltadas para o desenvolvimento da comercialização de forma digital, deste modo, esperou-se que houvesse a instauração de um caminho a ser seguido por outros segmentos de mercado.

\subsubsection{TREINAMENTO PARA GERENCIAMENTO DE SERVIÇOS TERCEIRIZADOS DE DELIVERY (5W2H)}

$\mathrm{Na}$ atualidade globalizada, a fim de que os gestores sejam capazes de manter as organizações estabilizadas e despertarem o crescimento mediante seus concorrentes, os gestores e coordenadores empresariais devem renovar-se e sempre recorrer a novos métodos para que possam, de maneira efetiva e produtiva, desenvolver suas vendas, ofertar seus produtos e concluir seus serviços com excelência. Deste modo, adota-se como estratégia para impulsionar a área de comercialização os procedimentos específicos de gestão relacionados a serviços de delivery terceirizados. Sendo assim, a adesão e manuseio destes procedimentos não é de grande dificuldade, no entanto, necessita de correlatos processos de capacitação.

RC: 100622

Disponível em: https://www.nucleodoconhecimento.com.br/administracao/novosclientes 
Quadro 06: Treinamento para gerenciamento de serviços terceirizados de delivery

\begin{tabular}{|c|c|c|}
\hline \multicolumn{3}{|c|}{ Treinamento para gerenciamento de serviços terceirizados de delivery } \\
\hline What & O quê? & $\begin{array}{l}\text { Inserir conhecimentos sobre as ferramentas e métodos de } \\
\text { atendimento virtual no processo de delivery. }\end{array}$ \\
\hline Why & Por quê? & $\begin{array}{l}\text { Para produzir satisfação em relação a este serviço oferecido } \\
\text { aos consumidores. }\end{array}$ \\
\hline Where & Onde? & Nos setores de marketing e atendimento. \\
\hline When & Quando? & Primeira semana de novembro de 2021 \\
\hline Who & Quem? & Setores gerenciais e de marketing. \\
\hline How & Como? & $\begin{array}{l}\text { Desenvolver treinamento digital por meio de uma plataforma } \\
\text { específica. }\end{array}$ \\
\hline $\begin{array}{l}\text { How } \\
\text { Much }\end{array}$ & Quanto? & $\mathrm{R} \$ 1.000,00$ \\
\hline
\end{tabular}

Fonte: Autores, 2021.

Diante do cenário apresentado ao longo da análise da empresa, bem como em conformidade aos dados acima apresentados, nota-se que esta ação de treinamento irá desenvolver conhecimentos e métodos inerentes ao atendimento virtuais, especialmente sobre a gestão do canal de distribuição das entregas por meio de delivery. A referida ação deve ocorrer a partir da primeira semana de novembro de 2021. Os setores gerencial e de marketing responsabilizam-se por sua introdução. Esta ação corretamente aplicada deverá impulsionar as vendas e a satisfação por conta da comodidade e do melhor atendimento, devendo-se estreitar o relacionamento entre clientes e organização.

\section{CONSIDERAÇÕES FINAIS}

Analisou-se no presente estudo os setores operacionais da empresa Semog's Comércio de Medicamentos LTDA. que tinham diferentes performances, organização que, por meio do Diagnóstico Organizacional, revelou o Marketing como

RC: 100622

Disponível em: https://www.nucleodoconhecimento.com.br/administracao/novosclientes 
o setor mais crítico devido a problemas internos, porém, de acessível decifração. A explanação e introdução dos objetivos foram manuseados no decorrer da comprovação teórica, na qual, com clareza e austeridade, os itens foram supramencionados metodicamente, convergentes às bases prescritas nas intervenções. Sendo assim, destaca-se o objeto geral em abordar a identificação de como a introdução de técnicas voltadas ao marketing digital e de serviços pode incrementar o desempenho de vendas. O estudo baseou-se em entender a problemática da pesquisa, que visa conceituar: Como estratégias de capacitação voltadas ao marketing de serviços e ao digital, integradas ao atendimento na empresa, podem amplificar o desempenho das vendas? Compreende-se que a partir da introdução de capacitações voltadas ao aprimoramento e gerenciamento da loja física, bem como treinamentos para prospecção de clientes e desenvolvimento de estratégias de marketing digital, aliadas ao treinamento para gerenciamento dos serviços terceirizados de entrega, esquematizaram um conjunto de ações interventivas que podem redirecionar os processos a novos índices de eficiência em suas operações e, por conseguinte, ampliar o desempenho das vendas. A respeito dos objetivos específicos, propôs-se: explorar as formas de treinamento em marketing de serviços; abordar a inserção de tais treinamentos na loja física e balcão virtual; e dimensionar os resultados obtidos com a abordagem das técnicas de serviço aplicadas. O marketing abrange diversas ações e formas de divulgação que visam o avanço, no entanto, com estes na organização, tornou-se necessário o aprimoramento do gerenciamento de estoques e setores produtivos.

O objetivo era o de possibilitar o correto suprimento das necessidades do mercado e produzir satisfação em relação aos serviços oferecidos aos consumidores. Dentre as imperfeições abordadas, salientaram-se a ausência de treinamentos para: o gerenciamento das operações, prospecção de novos clientes, desenvolvimento de estratégias em marketing digital e para gerenciamento de serviços terceirizados de delivery. Todavia, conclui-se que os métodos exercitados se tornaram satisfatórios no espaço institucional e formularam-se novos modelos de desenvolvimento organizacional, cuja capacitação no marketing e no gerenciamento estratégico

$\mathrm{RC}: 100622$

Disponível em: https://www.nucleodoconhecimento.com.br/administracao/novosclientes 
constituiu-se um grande avanço organizacional a partir de sua completa implementação, atendendo, assim, o propósito do estudo, que se remeteu a construir um conjunto de ações que solucionassem a demanda da empresa. Deixou, além disso, um legado para comunidade acadêmica, fornecendo base para futuros estudos.

\section{REFERÊNCIAS}

ALBERTIN, A. L.; BRAUER, M. Resistência à educação a distância na educação corporativa. Revista de Administração Pública, v. 46, n. 5, p. 1367-1389, 2012.

ASSIS, E. E.; OLIVEIRA, M. de. M. O Composto de Marketing de Serviços Correlacionado à Aplicação do Conceito de Hotelaria Hospitalar. Revista de Gestão em Sistemas de Saúde, v. 1, n. 2, p. 63-85, 2012.

BELTRÃO, M. da. C. As novas formas telemáticas e cibernéticas de trabalho sob demanda: uma análise acerca da intermediação das plataformas digitais nas relações laborais nos serviços de delivery à luz da Consolidação das Leis Trabalhistas. 2019. 53f. Monografia (Bacharel em Direito) - Universidade Federal de Pernambuco, Recife, PE, 2019.

CUNHA, A. U. do. N. Mapeamento de processos organizacionais na UnB: caso Centro de Documentação da UnB - CEDOC. 2012. 73f. Monografia (Especialista em Gestão Universitária) - Universidade de Brasília, Brasília, DF, 2012.

DUTRA, A. D. Aplicação de gamificação no ambiente virtual de aprendizagem moodle usando o framework 5w2h. 2018. 82f. Trabalho de Conclusão de Curso (Bacharel em Ciência da Computação) - Universidade do Extremo Sul Catarinense, Criciúma, SC, 2018.

FERREIRA, M. P. Como estruturar e escrever um artigo em administração. Revista Ciências Administrativas, v. 20, n. 2, p. 423-451, 2014. 
KRIPKA, R. M. L.; SCHELLER, M.; BONOTTO, D. de. L. Pesquisa documental na pesquisa qualitativa: conceitos e caracterização. Revista de investigaciones UNAD, v. 14, n. 2, p. 55-73, 2015.

LEMES, L. B.; GHISLENI, T. S. Marketing Digital: uma estratégia de relacionamento de marca. In: XIV Congresso de Ciências da Comunicação na Região Sul, 2013.

MENEGON, E. M. P.; ZAMBARDA, A. B. Percepção de colaboradores sobre as ações de treinamentos em uma indústria têxtil. Navus: Revista de Gestão e Tecnologia, v. 9, n. 1, p. 7-20, 2019.

MINAYO, M. C. de. S. Amostragem e saturação em pesquisa qualitativa: consensos e controvérsias. Revista pesquisa qualitativa, v. 5, n. 7, p. 1-12, 2017.

PEREIRA, V. T.; CASTILHO, A. P.; BORGES, N. R. M. Manual de metodologia científica do ILES Itumbiara/GO. Itumbiara: ILES/ULBRA, 2011.

SILVA, J. S. O mapeamento de processos organizacionais no setor público: estudo de caso do escritório de processos da Agência Nacional de Vigilância Sanitária - ANVISA. 2014. 59f. Monografia (Bacharel em Gestão de Políticas Públicas) - Universidade de Brasília, Brasília, DF, 2014.

SILVA, L. L. da.; CRUZ, C. A. B. da. Marketing digital: marketing para o novo milênio. Revista Científica do ITPAC, v. 7, n. 2, 2014.

SOUZA, T. E. S. et al. Metodologia científica: teoria e aplicação na educação a distância. Petrolina: Fundação Universidade Federal do Vale do São Francisco, 2019.

TOLEDO, G. L.; MORETTI, S. L. do. A. Valor para o Cliente e Valor do Cliente: Conceitos e Implicações para o Processo de Marketing. Desenvolvimento em Questão, v. 14, n. 35, p. 400-419, 2016.

Enviado: Setembro, 2021

RC: 100622

Disponível em: https://www.nucleodoconhecimento.com.br/administracao/novosclientes 
Aprovado: Novembro, 2021.

RC: 100622

Disponível em: https://www.nucleodoconhecimento.com.br/administracao/novosclientes 